\title{
Reflexiones sobre las modificaciones al régimen de locaciones: ley 27.551 y resolución AFIP 4933/2021
}

\section{POR MAURO F. LETURIA(*) Y ADRIÁN E. GOCHICOA(**)}

\begin{abstract}
Sumario: I. Introducción.- II. Consideraciones generales sobre el contrato de locación.- III. Modificaciones principales de la ley 27.551 y normativa de emergencia.- IV. Reflexiones finales.- V. Bibliografía.
\end{abstract}

Resumen: el contrato de locación es utilizado como un mecanismo para poder abordar una problemática que aqueja a gran parte de la población: el acceso a una vivienda digna. Las distintas regulaciones partieron desde el Código de Vélez Sarsfield y subsiguientes leyes, especialmente la ley 21.342 de locaciones urbanas, sobre la base de postulados como la igualdad y libertad formal de las partes. Paulatinamente, estas concepciones se fueron atenuando en torno a los contratos de locación para uso familiar. Con la sanción del Código Civil y Comercial se elimina la histórica división legal tripartita del contrato de locación, concibiéndose al locatario como la parte más débil de la relación contractual, y con esta finalidad, o al menos eso se intentó, se sanciona la ley 27.551 y la resolución de AFIP No 4933/2021. Si bien la exigencia de registrar los contratos del artículo 16 de la ley 27.551, reglamentada por la resolución de AFIP 4933/2021, no constituye un nuevo impuesto, sí demandará la realización de trámites y gestiones, que, de ser encargadas a profesionales tales como contadores o corredores, generaran un costo extra.

Palabras claves: locaciones de inmuebles - ley 27551- resolución AFIP 4933

$\left(^{*}\right)$ Procurador, abogado y escribano. Esp. en Docencia Universitaria. Doctorando de la Facultad de Ciencias Jurídicas y Sociales, (UNLP). Realizó estudios de postgrado sobre Derechos de Autor, Universidad Complutense de Madrid. Prof. en grado y posgrado, Facultad de Ciencias Jurídicas y Sociales, Universidad Nacional de La Plata (UNLP). Prof. en grado, Facultad de Derecho y Ciencias Políticas, Universidad Católica de La Plata (UCALP). Prof. en grado de la Universidad del Este. Prof. invitado en la Universidad Complutense de Madrid. Oficial de la Justicia Federal Argentina. Becario Doctoral del Ministerio de Educación de la Nación. Secretario de Extensión y de Investigación, Facultad de Derecho de la Universidad del Este.

(**) Abogado. Auxiliar Docente Contratos Modernos, Tecnicatura de Martillero y Corredor, Facultad de Ciencias Jurídicas y Sociales, Universidad Nacional de La Plata (UNLP). Colaboradora: Ab. Victoria Antonella Mongelos. 
Reflections about the modification of the leases of real estate system. Law No. 27551, AFIP's Resolution No. 4933

Abstract: Tenancy agreement as a mechanism is used to deal with the access to a decent housing, problematic that affects a large portion of the population. The different regulations started from the Velez Sarsfield Code and subsequent laws, in particular the Law of Real-estate Leases No. 21.342, based on tenets of contractual partie's equality and formal freedom. These conceptions were gradually waning around the family tenancy agreement. Tenancy agreement's tripartite historical legal division is deleted by the approval of the Civil and Commercial Code (Código Civil y Comercial de la Nación or CCCN), hence the lessee is conceived as the weakest of the contractual relationship. New sanctions of the law 27.551 and AFIP'S resolution 4933/2021 were trying to keep on with the same orientation. Even though, the contract registration requirement form 16 th article of the law 27.551 and its reglamentation AFIP's resolution 4933/2021 does not represent a new tax, but it will incur administrative processes and procedures that if a professional carried them out, such as accountant or agents, they will have an extra cost.

Keywords: Leases of real estate - Law No. 27551 - AFIP's Resolution No. 4933

\section{Introducción}

La doctrina clásica siguió lo desarrollado por el derecho romano; así, Vélez estableció en su Código el contrato de locación, regulando en forma conjunta la locación de cosas, la locación de servicios y la locación de obras.

Según el artículo 1493 del Código Civil de Vélez, "habrá locación cuando dos partes se obliguen recíprocamente, la una a conceder el uso o goce de una cosa, o a ejecutar una obra, o prestar un servicio; y la otra a pagar por este uso, goce, obra o servicio un precio determinado en dinero. El que paga el precio, se llama en este Código locatario, arrendatario o inquilino, y el que lo recibe locador o arrendador. El precio se llama también arrendamiento o alquiler".

La forma elegida por Vélez, que contempla las tres variantes posibles de contratos de locación, es decir, la "locación de cosas", la "locación de obra" y la "locación de servicios", no generó en su aplicación práctica, en los muchos años que rigió esta disposición, grandes controversias, pues solo se conocen disputas o discusiones tendientes a determinar el punto de separación en casos complejos, entre el contrato de locación de servicios y el de locación de obra, los que fueron resueltos tanto por la doctrina como por la jurisprudencia, sin mayores esfuerzos. Con la irrupción del derecho laboral y por el carácter de sus disposiciones, el contrato de locación de servicios, en el cual el prestador resulta ser una persona física, fue 
perdiendo progresivamente aplicación al ser absorbido o comprendido en la gran mayoría de las situaciones judicializadas por la Ley de contrato de trabajo.

Resulta de nuestro mayor interés la locación de cosas y más específicamente la locación de cosas inmuebles ubicadas en zonas urbanas, para lo cual, además de la normativa general establecida en el Código Civil, se sancionó posteriormente la ley No 23.091, denominada Ley de locaciones urbanas, en la que se establecieron las particularidades y condiciones a las que debían sujetarse las partes que decidían realizar un contrato de locación de inmuebles ubicados en el radio urbano.

Con la sanción del Código Civil y Comercial se abandona esta tradición histórica, o sistematización tripartita, y se establece en forma separada el contrato de locación de cosas que incluye a las cosas muebles e inmuebles, procediéndose, mediante la derogación de la ley 23.091, a consolidar la regulación de este contrato en forma sistemática en el cuerpo del CCiv. y Com. Se legisla por separado, en el "contrato de obra" y el "contrato de servicios", pero dejando de lado la utilización del concepto de locación, estableciendo disposiciones comunes para ambos contratos, en los artículos 1262 a 1277 inclusive y luego disposiciones especiales para los contratos de obra y para los contratos de servicios.

En función de este cambio legislativo, solo corresponde utilizar la denominación cuando nos referimos al contrato mediante el cual el locador (propietario o no del bien) le otorga al inquilino o locatario el uso y goce de una cosa por un tiempo determinado a cambio de un canon en dinero.

En el año 2020 se volvió a afectar la sistematicidad buscada por el CCiv. y Com. al sancionarse la ley 27.551. Mediante esta nueva normativa se introdujeron modificaciones estableciendo reglas especiales para los contratos de locación de inmuebles, siendo el eje central de la regulación aquellas locaciones destinadas al uso habitacional. Nuevamente se pone en tela de juicio la regulación como una forma de intervención del Estado en el ámbito contractual, especialmente en cuanto al canon locativo se refiere. En tal sentido, se produce el pasaje de la existencia de una garantía estatal legal de no intervenir en la fijación de los cánones locativos (conforme al artículo 6 de la ley 21.342), hacia una regulación específica referida al modo de ajuste del canon locativo en las locaciones urbanas con fines habitacional. El fundamento de tal viraje se encuentra en entender a la locación con fines habitacionales, en sociedades como la nuestra hoy en día, uno de los contratos más importantes tendiente a fines sociales en cuanto posibilidad de acceso a una vivienda digna. 


\section{Consideraciones generales sobre el contrato de locación}

El contrato de locación de cosas, según el artículo 1187 del Código Civil y Comercial, (1) implica que el locador (propietario o no del bien) le otorga al inquilino o locatario el uso y goce de una cosa por un tiempo determinado a cambio de un canon en dinero.

Sus principales características consisten en ser un contrato:

- Consensual, debido a que para su perfeccionamiento solo se requiere el consentimiento de las partes.

- Bilateral, dado que ambas partes, locador y locatario, poseen obligaciones a su cargo.

- Oneroso: las obligaciones que nacen son recíprocas o interdependientes y de carácter pecuniario.

- Conmutativo, dado que las prestaciones de las partes son ciertas y conocidas, y deben guardar entre sí una adecuada relación de proporcionalidad o de cierta equivalencia.

- De tracto sucesivo, porque las prestaciones son periódicas y son pactadas para cumplirse durante un tiempo determinado.

- Nominado o típico, dado que el ordenamiento jurídico les ha dado una regulación legal propia.

- No formal, porque en principio no requiere forma alguna, salvo en el caso de las locaciones de inmuebles o cosas muebles registrables, que deben ser realizadas por escrito para su oponibilidad, es decir a los efectos probatorios, según el artículo 1188 del Código Civil y Comercial, sin contemplar sanción de nulidad ante su incumplimiento.

Las partes contractuales son el locador y el locatario, sin perjuicio de que cada parte pueda estar conformada por varias personas, y no deben confundirse con otros sujetos que ocasionalmente aparecen vinculados en estos contratos, tales como los fiadores o comúnmente denominados garantes, o con el o los corredores que suelen acercar a las partes mediante la celebración de un contrato de corretaje.

(1) Textualmente se señala que "Hay contrato de locación si una parte se obliga a otorgar a otra el uso y goce temporario de una cosa, a cambio del pago de un precio en dinero. Al contrato de locación se aplica en subsidio lo dispuesto con respecto al consentimiento, precio y objeto del contrato de compraventa". 
El locador es aquella persona (física o jurídica) que se compromete a brindar el uso y goce de un inmueble. Puede ser el propietario o usufructuario o un poseedor de dicho bien, ya que no requiere tener la capacidad para disponer del bien, sino que solo necesita tener su administración, o estar en condiciones de poder darlo en locación, ya que celebrar el contrato de locación es considerado un acto de mera administración, por lo cual puede ser realizado también por un mandatario o representante con poder general del locador.

El locatario es la persona física o jurídica que toma en arriendo o alquiler la cosa o cosas (el inmueble) para su uso y goce y paga un precio por ello. Solo se requiere la capacidad suficiente para obligarse.

En cuanto al objeto del contrato de locación el Código Civil y Comercial en el artículo 1192 dispone que pueden serlo toda cosa presente o futura determinada $o$ determinable en la medida de que su tenencia este en el comercio (2).

En cuanto a la finalidad o utilización que debe hacer el locatario de la cosa, el artículo 1194 del Código dispone(3) ante todo que lo determine la voluntad de las partes. En caso de no haberse acordado un destino, corresponde el que se da a cosas análogas en el lugar donde la cosa se encuentra o el que corresponde a su naturaleza. En caso de destino mixto, se entiende que es habitacional. Dentro del esquema del contrato de locación de inmuebles se distingue, por un lado, la regulación de aquella con fines habitacionales con una regulación en parte específica en los artículos 1196, 1197, 1221 inc. a, 1221 bis, entre otros del CCiv. y Com., a lo que debe sumarse las disposiciones especiales de la ley 27.551, que tienen una pretendida tendencia a tutelar al inquilino como la parte más débil del contrato; mientras que, por el otro, aparecen el resto de las locaciones de cosas, con otros fines, cuya regulación está establecida en el CCiv. y Com., en las cuales la relación entre las partes debe ser analizada acorde a un estatus de paridad negocial salvo supuestos especiales en los cuales pudieran ser de aplicación las normas propias del derecho de consumo.

Corresponde señalar que estas disposiciones con relación al uso de la locación son propias o especiales para este contrato, y funcionan en forma supletoria a la

(2) El artículo 1192 señala que toda cosa presente o futura, cuya tenencia esté en el comercio, puede ser objeto del contrato de locación, si es determinable, aunque sea solo en su especie. Se comprenden en el contrato, a falta de previsión en contrario, los productos y los frutos ordinarios.

(3) El artículo 1194 señala: "Destino de la cosa locada. El locatario debe dar a la cosa locada el destino acordado en el contrato. A falta de convención, puede darle el destino que tenía al momento de locarse, el que se da a cosas análogas en el lugar donde la cosa se encuentra o el que corresponde a su naturaleza. A los efectos de este Capítulo, si el destino es mixto se aplican las normas correspondientes al habitacional". 
voluntad de las partes. Es posible que las partes pacten un uso distinto al habitual, pero siempre deben respetar que dichos acuerdos no se opongan a las reglas sobre el objeto de los actos jurídicos y de los contratos en general, para completar en forma integral cualquier análisis o situación problemática que se presente en relación con el objeto, en función de lo que ellas hayan establecido en el contrato; asimismo, no hay que olvidar que de la parte final del artículo 1187 del Código se desprende que, de manera subsidiaría, también se puede recurrir a lo dispuesto en este sentido para el contrato de compraventa. Conforme surge de los artículos 1197, 1198, y 1199 del Código Civil y Comercial, además de la finalidad habitacional pueden mencionarse la finalidad turística (4), la de guardado de cosas, entre otras.

Con relación a la forma, el artículo 1188 del Código Civil y Comercial(5) establece para las cosas inmuebles y muebles (Inclusive para una universalidad que incluya a alguna de ellas, o de parte material de un inmueble registrable) que la voluntad de las partes se exteriorice de manera escrita.

Hay que señalar que esta exigencia de forma solo es requerida para la locación de bienes inmuebles o muebles registrables y para universalidades que los incluya, es decir que para el resto de las cosas muebles no se requiere ninguna forma impuesta por la ley, con lo cual, las partes podrán usar la que consideren conveniente. Con relación a los efectos de esta exigencia, hay que concluir en que pese a la utilización de la frase "(...) debe ser hecho por escrito" en el artículo señalado, que parece indicar su obligatoriedad, la ausencia de sanción en caso de incumplimiento, sumado a la función instrumental de la forma considerada históricamente para el contrato de locación por la jurisprudencia y la doctrina, y dado que el comienzo del artículo tiene como consigna la palabra "oponibilidad", ninguna duda debe existir al respecto de que la exigencia de la forma escrita en los contratos de locación de inmuebles y muebles registrables es realizada a efectos probatorios y de oponibilidad frente a terceros (6), es decir, no tiene ninguna incidencia en el perfeccionamiento del contrato que se determina con el acuerdo de voluntades

(4) La ley 27.221 estableció que los contratos de locación de inmuebles que se celebren con fines turísticos, descanso o similares y cuyo plazo sea inferior a tres (3) meses conforme lo establecido en el inciso b), del artículo 1199, del Código Civil y Comercial de la Nación, se regirán por las normas aplicables al contrato de hospedaje.

(5) El artículo 1188 señala que el contrato de locación de cosa inmueble o mueble registrable, de una universalidad que incluya a alguna de ellas, o de parte material de un inmueble, debe ser hecho por escrito. Esta regla se aplica también a sus prórrogas y modificaciones.

(6) Este punto merece ser aclarado, no debiendo confundirse el derecho personal del locatario con un derecho real. En este caso, la forma instrumental no solo es impuesta como medio probatorio sino también como medio publicitario del contrato. En este último sentido, el artículo 1188 debe interpretarse de conformidad al artículo 317 del Código Civil y Comercial. 
de las partes; por lo tanto, la instrumentación o realización de la forma requerida podría perfectamente realizarse en un momento coetáneo con la celebración del contrato o en un momento posterior, y hasta podría no ser realizada nunca; esto implica que si un contrato de locación de inmueble es celebrado, por ejemplo, oralmente, el mismo será perfectamente válido entre las partes y producirá todos sus efectos legales, solo que por no haberse dado cumplimiento a la forma escrita pedida por la ley, en caso de conflicto, las partes tendrán dificultades probatorias que deberán resolver mediante otros medios de prueba.

Un supuesto particular, introducido por el Código Civil y Comercial de la Nación, relacionado con la trasmisión del contrato de locación, surge de lo establecido en el artículo 1190, en cuanto dispone:

Si la cosa locada es inmueble, o parte material de un inmueble, destinado a habitación, en caso de abandono o fallecimiento del locatario, la locación puede ser continuada en las mismas condiciones pactadas, y hasta el vencimiento del plazo contractual, por quien lo habite y acredite haber recibido del locatario ostensible trato familiar durante el año previo al abandono o fallecimiento. El derecho del continuador en la locación prevalece sobre el del heredero del locatario.

Este nuevo derecho, que podríamos denominar "derecho del o la continuador/a de la locación", no estaba previsto en el Código de Vélez, pero fue siendo reconocido por distintas decisiones jurisprudenciales (7) basadas en la protección de la familia y principalmente de la concubina o conviviente, que al no ser heredera y no haber formado parte del contrato originario, si ocurría el abandono o el fallecimiento de su pareja, se veía desprotegida y podía ser obligada a abandonar su vivienda.

El nuevo código también se inclina a brindar una mayor protección a los inquilinos frente a los locadores, que tratan de establecer limitaciones o cláusulas de claro contenido discriminatorio. Ello se observa en lo dispuesto en el artículo 1195 del Código Civil y Comercial, que expresamente dispone: "Habitación de personas incapaces o con capacidad restringida. Es nula la cláusula que impide el ingreso, o excluye del inmueble alquilado, cualquiera sea su destino, a una persona incapaz o con capacidad restringida que se encuentre bajo la guarda, asistencia $o$ representación del locatario o sublocatario, aunque este no habite el inmueble". Norma que debe interpretarse de orden público e imperativo (artículos 12 y 962 del CCiv. y Com.).

(7) Expte. No 79.315/11 - “E, D. c/ J., E. y Otro s/ Desalojo: Intrusos” - CNCIV. - SALA H - 21/12/2012. Publicado por elDial.com - AA7CCB el 04/03/2013; ORTIZ DE ELGUEA, AURORA c/ FLORIO VDA. DE GARCIA, ADELAIDA Y OTRA s/ DESALOJO. C.N.A.C., 12/03/1992, entre otros. 
Para los casos de cesión y sublocación, el Código Civil y Comercial dispone normas regulatorias de la "cesión y sublocación"; así el artículo 1213 establece: "Cesión. El locatario solo puede ceder su posición contractual en los términos previstos en los artículos 1636 y siguientes. La cesión que no reúna tales requisitos viola la prohibición de variar el destino de la cosa locada. La prohibición contractual de ceder importa la de sublocar y viceversa. Se considera cesión a la sublocación de toda la cosa".

La cesión de la posición contractual implica una decisión voluntaria por la cual la parte pretende su sustitución total en el contrato, que es regulada por el CCiv. y Com. para todos los contratos en el artículo 1636 y siguientes, aunque en el caso de la locación comprende la de sublocar como una forma de cesión parcial del contrato. Con relación específica a la sublocación, el artículo 1214 establece:

Sublocación. El locatario puede dar en sublocación parte de la cosa locada, si no hay pacto en contrario. Para ello debe comunicar al locador, por medio fehaciente, su intención de sublocar e indicarle el nombre y domicilio de la persona con quien se propone contratar, y el destino que el sublocatario asignará a la cosa. El locador sólo puede oponerse por medio fehaciente, dentro del plazo de diez (10) días de notificado. El silencio del locador importa su conformidad con la sublocación propuesta. La sublocación contratada pese la oposición del locador, o con apartamiento de los términos que se le comunicaron, viola la prohibición de variar el destino de la cosa locada.

\section{Modificaciones principales de la ley 27.551 y normativa de emergencia}

\section{III.1. Introducción}

En el año 2020 se sancionó la ley 27.551, conocida vulgarmente como ley de alquileres, que dado su técnica legislativa, por un lado, generó reformas y modificaciones al Código Civil y Comercial de la Nación, pero también mantiene vigencia propia estableciendo, como lo indica su título II, una "regulación complementaria de las locaciones"; también creó el "Programa Nacional de Alquiler Social” y, finalmente, en el título IV se reguló sobre "Métodos alternativos de resolución de conflictos", por lo cual, en la actualidad el contrato de locación de cosas inmuebles se encuentra regulado por el Código Civil y Comercial y ciertas disposiciones de esta ley.

La ley 27.551 fue el resultado de arduas negociaciones políticas, también entre diferentes sectores sociales y económicos involucrados, en la búsqueda de mejorar la situación de millones de inquilinos que se venía deteriorando por las 
sucesivas crisis económicas por las que atraviesa la República Argentina. Esta situación crítica se agravó dada la pandemia mundial de COVID-19 y la extensa cuarentena obligatoria ordenada por el Estado Nacional durante el año 2020. Tan profunda fue la crisis que también generó el dictado del Decreto de Necesidad y Urgencia 320/2020, que, en lo sustancial, suspendió los juicios de ejecución por cobro de alquileres y los desalojos por falta de pago del canon por el término de 6 meses, siendo prorrogados los plazos de las suspensiones previstos a través del Decreto 766/2020 hasta el 31 de enero de 2021 y, consiguientemente, el Decreto $66 / 2021$ realiza la prórroga de las medidas tomadas por los Decretos 320/2020 y 766/2020, extendiéndose hasta el 31 de marzo de 2021.

La solución no es novedosa. En esta materia encontramos distintas disposiciones legales con un punto en común: la limitación a la libertad contractual de las partes. Características comunes en sus disposiciones denotan congelamientos del canon locativo o bien prorrogaciones de los plazos de duración de los contratos de locación, que inevitablemente conllevan a su vez la continuación de contratos conexos al de locación como la fianza.

Aun cuando la principal finalidad del decreto y sus sucesivas prórrogas ha sido la protección de los locatarios, se estableció un marco de protección para los locadores, la cual se aplicaría a aquellos que se encuentren en una situación tal que los ubique en un estado de vulnerabilidad en tanto el canon locativo percibido por el arrendamiento de su propiedad signifique un factor necesario, sin el cual se encontrarían imposibilitados de poder afrontar sus necesidades básicas. En ese sentido, se dispone que el contrato continúe en los términos originalmente pactados, a la vez que coloca en cabeza del locador la carga de probar el supuesto fáctico merecedor de la protección establecida por la norma (8).

Si bien la ley fue presentada como un nuevo sistema a favor o en beneficio de los inquilinos, del análisis del conjunto de sus disposiciones (y aunque en alguna de ellas pueden observarse beneficios a los inquilinos a costa de los intereses de los locadores), en general y dados la existencia y agravamiento de los problemas estructurales de la Argentina - tales como la falta de viviendas, el costo dolarizado de las propiedades, la inflación o depreciación monetaria y demás dificultades para el acceso a una vivienda digna - esta ley dista mucho de constituir un sistema de normas coherentes que cumplan con su pretendido objetivo.

(8) Decreto 320/20, “Artículo 10.- Excepción - Vulnerabilidad del locador: Quedan excluidos de lo dispuesto en el artículo $4^{\circ}$ del presente decreto los contratos de locación cuya parte locadora dependa del canon convenido en el contrato de locación para cubrir sus necesidades básicas o las de su grupo familiar primario y conviviente, debiéndose acreditar debidamente tales extremos". 
Sin perjuicio de que dada su reciente sanción será el tiempo el que nos permita evaluarla, en esencia constituye intervenciones estatales en un mercado muy complejo, que, por un lado, afectan la sistemática que el CCiv. y Com. tenía y por el otro aumentan la falta de certeza imprescindible para la realización y cumplimiento de contratos de duración como es el caso de la locación de inmuebles.

Algunas disposiciones de la ley resultan innecesarias, ya que reiteran reglas existentes o soluciones a las cuales la doctrina y la jurisprudencia habían arribado sin dificultad; mientras que otras resultan dañinas para las partes por aumentar conflictividad o su incertidumbre y también para el resto de sectores involucrados en la actividad, como la construcción y las inmobiliarias, pues desalientan la inversión. Sabido es que, al tornar más gravoso o burocrático el desarrollo de sus actividades - porque la realización de más trámites y gastos, y las situaciones de incertidumbre en la actividad repercuten directamente en el precio del alquilerse dificulta el acceso de los inquilinos a una vivienda digna o lo hace más gravoso en relación con sus ingresos.

\section{III.2. Reformas formales}

Dentro de esta arista pueden mencionarse cambios e incorporaciones de aspectos no sustanciales ni referidos a la estructura contractual.

Así respecto al domicilio convencional se modificó el artículo 75 del CCiv. y Com. al solo efecto de introducir el domicilio especial electrónico para todo supuesto convencional, más allá del ámbito locativo.

En este sentido debe señalarse que el Código Civil y Comercial define al "domicilio" como el lugar de residencia habitual y el principal asiento de los negocios, si se ejerce actividad económica (artículo 73), no siendo técnicamente exacto asimilarlo con una dirección electrónica, ya que aquel es un concepto más amplio abarcando tanto relaciones jurídicas contractuales como extracontractuales, y transmisiones de derechos entre vivos como mortis causa.

Se entiende que la finalidad de la norma es introducir una simplificación en cuanto a las comunicaciones y notificaciones que surjan en el marco de una relación contractual, cuestión que ya estaba posibilitada en virtud del principio de autonomía de la voluntad. Expresamente se regula sobre el domicilio especial convencional en el artículo 1201 del CCiv. y Com. referido a reparaciones locativas, y en el artículo 1222 respecto a la intimación de pago y desalojo, indicándose en ambos casos que la notificación remitida al domicilio denunciado por el locador en el contrato se tendrá por válida, aun si el locador se negara a recibirla o no pudiese perfeccionarse por motivos imputables al mismo. 


\section{III.3. Reformas sustanciales}

Con relación a las reformas sustanciales, las modificaciones pueden analizarse siguiendo la estructura de la regulación del Código Civil y Comercial de la Nación, sin perjuicio de que la ley 27.551 altera dicha sistemática dificultando su interpretación.

\section{III.3.1. Régimen de Garantías}

En el punto referido a la regulación del régimen de garantías, en las locaciones inmobiliarias con fines habitaciones, la ley 27.551 modifica el artículo 1196 señalándose con la nueva redacción que no podrá requerirse al locatario:

a) El pago de alquileres anticipados por períodos mayores a un mes; b) Depósitos de garantía o exigencias asimilables, por cantidad mayor del importe equivalente al primer mes de alquiler. El depósito de garantía será devuelto mediante la entrega de una suma equivalente al precio del último mes de la locación, o la parte proporcional en caso de haberse efectuado un depósito inferior a un mes de alquiler. El reintegro deberá hacerse efectivo en el momento de la restitución del inmueble. En el caso de existir alguna deuda por servicios públicos domiciliarios o expensas, correspondientes al período contractual y que al momento de la entrega del inmueble no hubiese sido facturada, puede acordarse su pago tomando al efecto los valores del último servicio o expensas abonado, o bien el locador puede retener una suma equivalente a dichos montos como garantía de pago. En este último caso, una vez que el locatario abone las facturas remanentes, debe presentar las constancias al locador, quien debe restituir de manera inmediata las sumas retenidas; c) El pago de valor llave o equivalentes; d) La firma de pagarés o cualquier otro documento que no forme parte del contrato original.

La modificación realizada se refiere, por un lado, al monto o quantum del depósito en garantía, limitándose ahora a un monto máximo del equivalente al primer mes de alquiler (en la redacción originaria del CCiv. y Com. el máximo era el importe equivalente a un mes de alquiler por cada año de locación contratado). Por otro lado, se establece un sistema de reintegro del mismo (más allá de la posibilidad de compensarlo o retenerlo como garantía) que, sumado al sistema de ajuste del canon locativo, resulta ser perjudicial para el locador y para el carácter conmutativo del contrato. Podrá discutirse si el monto del primer canon locativo resulta suficiente para garantir una relación contractual, que ahora tendrá un mínimo de 3 años y un máximo de 20, ya que con la nueva redacción el monto del depósito de la garantía siempre será del valor de un mes (del primer canon) independientemente de la duración del mismo, pero el locador al terminar el contrato 
deberá realizar la entrega de una suma equivalente al precio del último mes de la locación. El locador recibirá como depósito en garantía un valor, pero deberá restituir otro mayor conforme al sistema de ajuste regulado para el canon locativo, con el agravante de que no sabrá cuánto deberá devolver. El sentido común indica que es muy difícil mantener el valor actualizado de un monto de dinero recibido; imaginemos para ello que dicho monto deberá ser puesto en una inversión financiera rentable para compensar el hecho de que deba restituirse más de lo recibido o se exigirá que el mismo se realice en moneda extranjera en un valor equivalente al monto del primer canon, situaciones que no han sido previstas por la ley.

También, se incorpora la prohibición de exigir la firma de pagarés o cualquier otro documento que no forme parte del contrato original. En este punto debe señalarse que, si bien las partes no pueden en el contrato de locación manifestar el otorgamiento de pagarés o cualquier otro documento en garantía, al ser actos jurídicos abstractos (artículo 283 del CCiv. y Com.) -los cuales tienen una causa, o sea un porqué y un para qué (en este caso el ser una garantía)—, su otorgamiento no impedirá su posterior ejecución. En tal caso, debió haberse previsto por ley mecanismos para discutir abusos o la inexistencia, falsedad o ilicitud de la causa al momento de querer hacerse efectivo, tal como se ha entendido, en el denominado pagaré de consumo.

La interpretación jurisprudencial de disposiciones similares y el contenido claro e imperativo de estos artículos, nos lleva a concluir que pese a que los locadores inserten cláusulas o exijan requisitos como los descriptos y que los locatarios los hayan consentido o permitido mediante la firma del instrumento en el que se plasma el contrato, los inquilinos no estarán obligados a cumplirlos en función de estar amparados por estas disposiciones legales que son de orden público (artículos 12 y 962 del CCiv. y Com.).

La ley 27.551 en su artículo 13 señala como complemento a lo regulado en el Código con relación a las exigencias de garantías:

En las locaciones habitacionales, en el caso de requerirse una garantía, el locatario debe proponer al locador al menos dos (2) de las siguientes garantías: a) Título de propiedad inmueble; b) Aval bancario; c) Seguro de caución; d) Garantía de fianza o fiador solidario; e) Garantía personal del locatario, que se documenta con recibo de sueldo, certificado de ingresos o cualquier otro medio fehaciente. En caso de ser más de un locatario, deben sumarse los ingresos de cada uno de ellos a los efectos de este artículo. El locador no puede requerir una garantía que supere el equivalente a cinco (5) veces el valor mensual de la locación, salvo que se trate del supuesto previsto en el inciso e), en el cual puede elevarse dicho valor hasta un máximo de diez (10) veces. 
Agregándose que "bajo tales condiciones, el locador debe aceptar una de las garantías propuestas por el locatario".

De esta disposición deben notarse dos cosas: por un lado, su técnica legislativa deficiente, que hace que la regulación no sea incluida en el articulado del código, sino que se mantenga en la ley en forma complementaria, lo que dificulta su aplicación sistemática; por el otro, debe señalarse el carácter imperativo de la norma, que de acuerdo con su redacción literal indica que el inquilino propone garantías y el propietario "estaría obligado o debe elegir entre ellas". Ello contradice directamente el principio fundamental desarrollado en la teoría general del contrato, la libertad de contratar, ya que ante este supuesto nos encontraríamos con una supuesta limitación a dicho principio para la realización del contrato de fianza, lo cual es inadmisible dado que vulnera el principio de autonomía de la voluntad. Si un inquilino propone garantías que no resultan a criterio del locador suficientes, este último siempre tendrá la libertad de no contratar, y ello no resulta abusivo sino el ejercicio regular de su derecho. En este punto, también debe señalarse que mientras con estas garantías se intenta afianzar a todo el contenido o consecuencias económicas que surjan del contrato, los depósitos de garantías del artículo 1196 están referidos al pago por daños en la propiedad o cargas o créditos que surjan durante el transcurso de la relación contractual o para indemnizar la extinción anticipada del contrato.

\section{III.3.2. Plazo del contrato}

Con relación al tiempo de duración de la locación, la modificación en este punto no es tan trascendental como se la ha querido presentar. Por un lado, ya el Código Civil y Comercial innovaba en este sentido y había cambiado lo relativo a los plazos de la locación en forma sustancial con relación a lo vigente anteriormente. El Código Civil establecía plazos mínimos y máximos para la locación; así el artículo 1505 establecía que el contrato de locación no podía hacerse por mayor tiempo que el de diez años. El que se hiciere por mayor tiempo quedaría concluido a los diez años (sabida era la enérgica postura de Vélez con relación a que los contratos de locación no debían extenderse por muchos años dado que ello produce un deterioro en las cosas por falta de debido cuidado). Luego, según la ley 23.091 de locaciones urbanas, para las locaciones con destino a vivienda, con o sin muebles, se establecía el plazo mínimo de dos años. Para los demás destinos, comercio o industria, el plazo mínimo era de tres años.

Con la sanción del Código Civil y Comercial de la Nación, en el artículo 1197 se regula el plazo máximo señalando que "el tiempo de la locación, cualquiera sea su objeto, no puede exceder de veinte (20) años para el destino habitacional y cincuenta (50) años para los otros destinos. El contrato es renovable expresamente por un lapso que no exceda de los máximos previstos contados desde su inicio". Lo que debe ser completado acorde a lo establecido en el artículo 1198 que regula el 
plazo mínimo de la locación de inmueble, con lo cual puede rápidamente observarse del párrafo anterior que los plazos de duración de los contratos de locación han sufrido continuamente modificaciones y no resultaría novedoso si en un futuro cercano se vuelven a modificar.

En este sentido, la ley 27.551 modificó el artículo 1198 del CCiv. y Com. estableciendo que, en la actualidad, el contrato de locación de inmueble, cualquiera sea su destino, si carece de plazo expreso y determinado mayor, se considera celebrado por el plazo mínimo legal de tres años, excepto los casos del artículo 1199, y dejando a salvo que: "siempre el locatario puede renunciar a este plazo si está en la tenencia de la cosa cuando no fuera expreso".

Debe señalarse que se trata de una norma de orden público a favor del inquilino, que no puede ser dejada sin efecto por la voluntad de las partes. De tal manera que los contratos que se celebraren por términos menores serán considerados como formulados por los plazos mínimos indicados por la ley como una garantía a la estabilidad en el uso de la vivienda.

La extensión del plazo mínimo - se eleva de 2 a 3 años - busca dar mayor previsibilidad a los inquilinos, sobre todo a las familias, para que puedan establecerse en una vivienda con el fin de no hacerles vivir la incertidumbre de tener que renovar o mudarse continuamente, con los trastornos y gastos que ello conlleva. Resulta frecuente escuchar que con esta extensión del plazo mínimo los inquilinos deberían pagar menos gastos, al evitarse la renovación cada dos años, lo cual es posible en los casos de alquileres entre particulares; pero teniendo en cuenta que muchos contratos se realizan con la intermediación de un corredor matriculado y que de acuerdo a la legislación vigente sus honorarios se corresponden a un porcentaje del monto total del contrato, la extensión del plazo genera que el pago inicial sea superior ya que se tomará el monto del contrato que ahora por disposición de la ley será de tres años.

Se regulan como excepciones al plazo mínimo legal en el artículo 1199 (9), donde la modificación se refiere a las locaciones con fines turísticos, limitándose ahora a 3 meses.

(9) Para los contratos de locación de inmuebles o parte de ellos destinados a: a) Sede de embajada, consulado u organismo internacional, y el destinado a habitación de su personal extranjero diplomático o consular; b) Habitación con muebles que se arriende con fines de turismo, descanso o similares. Si el plazo del contrato o de los contratos consecutivos supera los tres (3) meses, se presume que no fue hecho con esos fines; c) Guarda de cosas; d) Exposición u oferta de cosas o servicios en un predio ferial. Tampoco se aplica el plazo mínimo legal a los contratos que tengan por objeto el cumplimiento de una finalidad determinada expresada en el contrato y que debe normalmente cumplirse en el plazo menor pactado. 


\section{III.3.3. Obligaciones del locatario}

En el punto referido a la regulación de las obligaciones del locatario, el Código Civil y Comercial dedica el parágrafo 2 de la sección 4ta a establecerlas, si bien no hay una jerarquización entre ellas. Sin embargo, nosotros entendemos que corresponde tratarlas según su importancia.

Así, la principal obligación del locatario consiste en la prevista por el artículo 1208, esto es, la de pagar el canon convenido (10).

En esta obligación se produce una de las principales reformas introducidas. La locación de cosas muebles o inmuebles es por un plazo determinado, como se mencionó anteriormente; durante este periodo, el locatario debe abonar el precio pactado al locador, en el primer caso tratándose de cosas muebles al contado y en el segundo en forma periódica. Dicho precio debe ser en dinero. La moneda extranjera resulta asimilada al dinero para estos supuestos, es decir, puede perfectamente pactarse que el precio del canon locativo se abone en una moneda extranjera, sin desnaturalizar el contrato de locación acorde a lo permitido por el artículo 766 del Código Civil y Comercial de la Nación.

Para probar la existencia del pago se puede recurrir a cualquier medio de prueba; uno de los más utilizados es el recibo. La emisión del mismo, sin reservas o cuestionamientos hace presuponer el pago efectivo de los anteriores períodos del alquiler, salvo prueba contraria.

En lo que interesa a las locaciones inmobiliarias, la ley 23.091, en el artículo 6, destinado a las locaciones con fines de vivienda, establecía que: “(...) el precio del arrendamiento deberá ser fijado en pagos que correspondan a períodos mensuales (...)”; dicha ley también disponía en el artículo 7 que: “(...) no podrá requerirse del locatario el pago de alquileres anticipados por períodos mayores de un mes".

Debe tenerse en cuenta que desde el año 1991, fecha en que se sancionó la Ley de convertibilidad, no está permitida la actualización monetaria, es decir, no es posible pactar una indexación o actualización del valor o monto de la obligación dineraria. A partir de la crisis del año 2002, con el dictado de la ley 25.561 de Emergencia Económica y frente a la derogación del régimen de convertibilidad, el cuadro de situación cambió y a la imposibilidad de indexar se le sumó una creciente inflación; por ello, las partes contractuales se dedicaron a buscar distintas

(10) El artículo citado señala que la prestación dineraria a cargo del locatario se integra con el precio de la locación y toda otra prestación de pago periódico asumida convencionalmente por el locatario. Para su cobro se concede vía ejecutiva. A falta de convención, el pago debe ser hecho por anticipado: si la cosa es mueble, de contado; y si es inmueble, por período mensual. 
variantes a la hora de definir el precio con el fin de mantener y proteger, de alguna manera, la equivalencia de las prestaciones entre locador y locatario. En este sentido, la fórmula más utilizada fue la de pactar "alquileres escalonados o progresivos". Ello implica pactar el precio total de toda la relación locativa, esto es, por un monto global y luego se lo divide en un valor mensual para un período, por ejemplo, del primer año, y otro mayor para el período siguiente.

También se presentaron muchos casos en los cuales las partes se obligaban a realizar una negociación periódica; esto implica que las partes pueden pactar que, en determinado tiempo, por ejemplo, cada seis meses, se renegociará el precio conforme al principio de buena fe contractual y las condiciones del mercado. Sin embargo, en caso de falta de acuerdo, puede interpretarse que, si se quiere dar por terminado el contrato por parte del locador, se afectaría el plazo mínimo establecido por el artículo 1198 del Código Civil y Comercial, que tiene la naturaleza de ser de orden público.

La ley 27.551 innova en esta cuestión estableciendo una excepción a la prohibición de indexar. Así, en su artículo 14, dispone que "Los contratos de locación, cualquiera sea su destino, están exceptuados de lo dispuesto en los artículos 7 y 10 de la ley 23.928 y sus modificatorias". La ley 26.944 dejo vigente los artículos citados de la ley 23.928. En términos de esta última ley citada, la indexación consiste en la repotenciación de las deudas o créditos en virtud de su ajuste por precios, actualización monetaria, variación de costos o índices; en otras palabras, reconocer un efecto directo entre la inflación y el monto nominal de una deuda.

Y es en este sentido que la ley 27.551, en el citado artículo 14, establece un sistema de ajuste anual del canon locativo en los contratos de locación de inmuebles destinados a uso habitacional (aunque también se exceptúa de los artículos 7 y 10 de la ley 23.928 a los contratos la locación que tengan otros fines, por lo que, en estos casos, podrá utilizarse otro sistema que no sea la combinación de los índices IPC y RIPTE).

Se establece que "el precio del alquiler debe fijarse como valor único y por períodos mensuales, sobre el cual solo pueden realizarse ajustes anuales. En ningún caso se pueden establecer bonificaciones ni otras metodologías que induzcan a error al locatario". En tales casos, "los ajustes deben efectuarse utilizando un índice conformado por partes iguales por las variaciones mensuales del índice de precios al consumidor (IPC) y la remuneración imponible promedio de los trabajadores estables (RIPTE), que debe ser elaborado y publicado mensualmente por el Banco Central de la República Argentina (BCRA)".

En conclusión, el precio o canon locativo, cuando de locaciones inmobiliarias con fines habitacionales se trate, debe ser un "valor único" (se prohíbe el precio 
escalonado), por "períodos mensuales" y repotenciado por "ajustes anuales" mediante la aplicación de los índices anteriormente señalados.

El sistema elegido por la ley para establecer el porcentaje de aumento del canon locativo para el caso de locaciones cuyo destino sea habitacional resulta cuestionable desde varios aspectos. En primer lugar, limita la voluntad de las partes al permitirles negociar solo el precio del alquiler mensual correspondiente al primer año, obligándolas, por imperio de la ley, en el segundo y tercer año a pagar lo resultante de la aplicación de dichos índices. El sentido de esta norma —si bien fue establecida para beneficiar a los inquilinos-difícilmente pueda sostenerse en un contexto de alta inflación. Además, agrega un elemento de incertidumbre ya que las partes no pueden saber cuánto efectivamente será el monto a pagar en el segundo y tercer año de contrato hasta que no llegue una fecha próxima a su cumplimiento.

Por otro lado, como otra obligación el artículo 1209 del Código Civil y Comercial, corresponde al inquilino "Pagar cargas y contribuciones por la actividad".

Conforme la modificación realizada por la ley 27.551:

El locatario tiene a su cargo el pago de las cargas y contribuciones que se originen en el destino que dé a la cosa locada. No tiene a su cargo el pago de las que graven la cosa ni las expensas comunes extraordinarias. Sólo puede establecerse que estén a cargo del locatario aquellas expensas que deriven de gastos habituales, entendiéndose por tales aquellos que se vinculan a los servicios normales y permanentes a disposición del locatario, independientemente de que sean considerados como expensas comunes ordinarias o extraordinarias.

La intención del legislador al formular este artículo era establecer una protección hacia los inquilinos que eran obligados a afrontar el pago de expensas o gastos extraordinarios que corresponden al dueño de la cosa. A pesar de ello, la redacción resulta confusa, ya que, por un lado, se excluyen de estar a cargo del locatario "el pago de las que graven la cosa o las expensas comunes extraordinarias", pero en el párrafo final permite que sí se les cobren gastos a los inquilinos "independientemente de que sean considerados como expensas comunes ordinarias o extraordinarias", si por algún mecanismo se establece que corresponden a servicios a su disposición. Lo cierto es que doctrinariamente la diferencia entre expensas ordinarias y extraordinarias no presentaba mayores dificultades, pero con la redacción de este artículo parece borrarse esas distinciones, ya que, según parece decir, no importa el nombre con que se las designe ni la naturaleza del gasto, en resumen de cuentas, estarán a cargo del locatario los gastos habituales entendiéndose por 
tales aquellos que se vinculan a los servicios normales y permanentes que estén a su disposición.

Sin perjuicio de lo señalado, lo cierto es que en nuestro ordenamiento jurídico la distinción de las "expensas" entre comunes ordinario y común extraordinarias a los efectos de asignar las cargas y contribuciones que deberán abonar el locatario y el propietario respectivamente, ya se encontraba regulada y definida en los artículos 2046 y 2048 del CCiv. y Com. referidos a la propiedad horizontal. Ahora, lo que debe realizarse es una interpretación armónica que permita considerar que esta nueva regulación es exclusivamente aplicable para los contratos de locación de inmuebles con destino habitacional, permitiendo su aplicación en supuestos en los cuales se pretende cobrar a los inquilinos gastos que no les corresponden.

Por último, el resto de las obligaciones no sufrieron modificaciones como la obligación del locatario de restituir la cosa (11), el usar y gozar de la cosa conforme a derecho y exclusivamente para el destino correspondiente(12), el mantener la cosa en buen estado (13).

(11) Como la naturaleza del contrato implica el traspaso de la tenencia de la cosa, debe también el locatario cumplir con su restitución con lo prescripto por el artículo 1210. Esta es una obligación fundamental, ya que el contrato de locación se da por finalizado con la entrega de la cosa. Mientras la entrega o devolución no se encuentre perfeccionada subsisten las obligaciones del locatario, y de alguna manera también de su fiador.

(12) Conforme al artículo 1205 del Código Civil y Comercial el locatario puede usar y gozar de la cosa conforme a derecho y exclusivamente para el destino correspondiente, sin variar su destino. El inquilino no tiene ninguna posibilidad de cambiar el destino de la cosa que se fijó en el contrato al momento de celebrar la locación; solo puede realizar dicho cambio con la anuencia del locador. Conforme al artículo 1206 el locatario debe mantener la cosa y conservarla en el estado en que la recibió. No cumple con esta obligación si la abandona sin dejar quien haga sus veces. Responde por cualquier deterioro causado a la cosa, incluso por visitantes ocasionales, pero no por acción del locador o sus dependientes.

(13) El mantenimiento de la cosa encuentra regulación en lo prescripto por el artículo 1207, en cuanto dispone que el inquilino debe mantener la cosa en buen estado tiene a su cargo el gasto de su conservación y las mejoras de mero mantenimiento; y solo estas si es inmueble. Si es urgente realizar reparaciones necesarias puede efectuarlas a costa del locador dándole aviso previo". A esto hay que sumar lo dispuesto en el parágrafo $3^{\circ}$, del artículo 1211, que establece que el locatario puede realizar mejoras en la cosa locada, excepto que esté prohibido en el contrato, alteren la substancia o forma de la cosa, o haya sido interpelado a restituirla. No tiene derecho a reclamar el pago de mejoras útiles y de mero lujo o suntuarias, pero, si son mejoras necesarias, puede reclamar su valor al locador. El artículo 1224 dispone que el locatario puede retirar la mejora útil o suntuaria al concluir la locación; pero no puede hacerlo si acordó que quede en beneficio de la cosa, si de la separación se sigue daño para ella, o separarla no le ocasiona provecho alguno. El locador puede adquirir la mejora hecha en violación a una prohibición contractual, pagando el mayor valor que adquirió la cosa. 
Aunque el Código no lo establece expresamente, también corresponde al inquilino dar aviso al locador de toda turbación de hecho o de derecho que sufra en el uso y goce del inmueble.

\section{III.3.4. Obligaciones de los locadores, resolución de AFIP 4933/2021}

Por otro lado, se introducen a cargo del locador (como regulación complementaria de las locaciones) obligaciones registrales con fines fiscales, y aun yendo más allá, como presupuesto para el ejercicio de la acción judicial correspondiente: en el artículo 15 de la ley 27.551, para el supuesto de que el locador de un inmueble se rehusare a cobrar el canon locativo, el locatario luego de intimarlo fehacientemente podrá consignar judicialmente el monto o utilizar un cheque cancelatorio (regulado en ley 25.345 y por las disposiciones del BCRA). Por su parte, el artículo 16 establece que los contratos de locación de inmueble deben ser declarados por el locador ante la Administración Federal de Ingresos Públicos de la Nación (AFIP), creándose un registro a tal efecto. Esta norma plantea conflictos en cuanto a las jurisdicciones fiscales propias de un Estado Federal, ya que se federaliza el registro de los contratos, y se otorga intervención procesal a un organismo que solo tiene facultades de control tributario federal al disponer que cuando se inicien acciones judiciales a causa de la ejecución de un contrato de locación, previo a correr traslado de la demanda, el juez debe informar a la AFIP sobre la existencia del contrato, a los fines de que tome la intervención que corresponda. Lo cierto es que la más adecuada interpretación constitucional, que resulte compatible con el artículo 75 inc. 12 y el artículo 121 de la Constitución Nacional (CN) indicaría que dicha obligación solo pueda exigirse en la jurisdicción federal, ya que de lo contrario se estaría modificando por una ley nacional las leyes procesales provinciales.

En función que la ley № 27.551, promulgada por el Gobierno Nacional mediante el decreto No 580 del 29 de junio de 2020, dispuso a través del artículo 16 que los contratos de locación de inmuebles deben ser declarados por el locador ante la Administración Federal de Ingresos Públicos, dentro del plazo, en la forma y con los alcances que dicho organismo disponga, la AFIP estableció mediante el dictado de la resolución 4933/2021 el "Régimen de Registración de Contratos de Locación de Inmuebles", con lo cual quedó reglamentado que contratos quedan alcanzados por la obligación de su registración; acorde al artículo 2:

Deberán registrarse a través del 'RELI', los contratos celebrados - por cuenta propia o por cuenta y orden de terceros- correspondientes a las operaciones económicas que se indican a continuación:

a) Locaciones (2.1.) de bienes inmuebles urbanos (2.2.), así como las sublocaciones (2.3.), cualquiera sea la denominación dada a los respectivos contratos. 
b) Arrendamientos sobre bienes inmuebles rurales (2.4.), así como los subarriendos (2.5.), con prescindencia de la modalidad o denominación que se le otorgue.

c) Locaciones temporarias de inmuebles - urbanos o rurales- con fines turísticos, de descanso o similares (2.6.).

d) Locaciones de espacios o superficies fijas o móviles - exclusivas o no- delimitados dentro de bienes inmuebles - vgr. locales comerciales y/o "stands" en supermercados, hipermercados, shoppings, centros, paseos o galerías de compras, complejos, centros o "polos" gastronómicos, culturales, complejos comerciales no convencionales (2.7.), ferias, mercados, centros de convenciones, multieventos o similares, terrazas, sótanos, azoteas, etc.-, cualquiera sea la denominación dada a los respectivos contratos (2.8.).

No están comprendidos dentro de este inciso los alquileres de espacios de 'góndolas' (2.9.).

En todos los casos, se encuentran incluidos los contratos de locación celebrados electrónicamente mediante la utilización de plataformas digitales y/o aplicaciones móviles destinadas a tal fin.

Si bien la ley 27.551 establecía que los locadores eran los sujetos obligados que tenían que realizar la registración del contrato de locación, la resolución, en su artículo 3, dispone:

Quedan obligados a efectuar la registración prevista en el artículo precedente, las personas humanas, sucesiones indivisas y personas jurídicas cualquiera sea la forma que adopten (3.1.), que asuman el carácter de locadores, arrendadores, sublocadores o subarrendadores, en los contratos celebrados. Cuando los inmuebles pertenezcan a sujetos residentes en el exterior, la obligación señalada estará a cargo de sus representantes en el país, cualquiera sea la modalidad de la representación.

$\mathrm{Si}$, como es de práctica frecuente en nuestro país, en la realización del contrato participa un intermediario, que acorde a la ley 27.551 , solo podría ser un profesional corredor matriculado, el artículo 5 dispone:

Cuando en los contratos celebrados intervengan intermediarios (5.1.), estos podrán registrarlos en representación de los locadores o arrendadores, debiendo cumplirse a tal efecto el procedimiento previsto en el Capítulo 7. 
La registración efectuada en estas condiciones implicará:

a) La excepción de dar cumplimiento a las obligaciones previstas por el presente régimen, para los locadores o arrendadores.

b) La confirmación de la participación en las operaciones económicas, para los intermediarios.

En ningún caso, ante incumplimientos en la registración de contratos, resultarán oponibles a esta Administración Federal las cláusulas contractuales, condiciones y términos del mandato y representación otorgados a los intermediarios, como eximentes de la responsabilidad que le cabe a los sujetos locadores o arrendadores.

Con lo cual, se desprende que la obligación corresponde siempre al locador y que en cada caso el profesional corredor matriculado interviniente solo está facultado a realizar la inscripción del contrato en su representación, pero no está obligado a hacerlo. Es importante resaltar que los profesionales no resultan sujetos obligados dado que, según el artículo 16 de la resolución de AFIP, "los datos ingresados a través del presente régimen revisten el carácter de declaración jurada en los términos del segundo párrafo del artículo 28 del decreto № 1.397 del 12 de junio de 1979 y sus modificaciones, reglamentario de la ley No 11.683, texto ordenado en 1998 y sus modificaciones", por lo tanto si deciden realizar o asumir la tarea de registrar los contratos serán responsables por la veracidad de los datos aportados.

Si bien, en principio, la obligación de registración de los contratos de locación de inmuebles aparece como una obligación formal, o de carácter informativo, lo cierto es que generará impactos sustanciales en los locadores, dependiendo su situación patrimonial. Por ejemplo, si es propietario de un inmueble que se encuentra alquilado, tiene que inscribirse en AFIP y cumplir con las obligaciones que le corresponden como locador. Para el caso que resulte monotributista, es decir que la totalidad de tu facturación anual no debe superar $\$ 1.739 .493,79$, no debe tener más de tres unidades de explotación o más de tres actividades económicas desarrolladas (cada inmueble alquilado constituye una unidad de explotación). $\mathrm{Al}$ celebrar un contrato de alquiler deberán emitir comprobantes tipo " $\mathrm{C}$ " y tener declarados los inmuebles en la presentación de bienes personales.

Si el locador se encuentra inscripto en el Régimen General (IVA y Ganancias), es decir que la totalidad de tu facturación anual supera $\$ 1.739 .493,79$, tiene más de tres unidades de explotación o actividades económicas, deberá emitir comprobantes tipo "B" a los consumidores finales o exentos en IVA, presentar las 
declaraciones juradas y cumplir con obligaciones del Portal IVA y declarar las rentas en la presentación anual de ganancias y el inmueble en bienes personales.

La reglamentación de la AFIP establece un procedimiento informático para que se dé cumplimiento a la obligación de registración; acorde al artículo 7:

Para registrar los contratos celebrados por las operaciones económicas indicadas en el artículo 2, los sujetos obligados deberán ingresar, a través del sitio "web" de este Organismo (http://www.afip.gob.ar) al servicio denominado "Registro de Locaciones de Inmuebles - RELI CONTRIBUYENTE". A tales fines, utilizarán la respectiva "Clave Fiscal" habilitada con Nivel de Seguridad 3 como mínimo, obtenida de acuerdo con lo previsto por la Resolución General No 3.713, sus modificatorias y complementarias.

Dentro de dicho servicio, por cada contrato celebrado, deberán acceder a la opción "Declaración de contratos", seleccionar si se trata de bienes inmuebles urbanos o rurales y la modalidad de la operación - permanente o temporaria-, proporcionar los datos detallados en los Anexos II y III que correspondan y adjuntar en un archivo en formato ".pdf" o ".jpg" el contrato celebrado.

Con relación al plazo de cumplimiento, la reglamentación establece como regla general para los futuros contratos en vigencia a partir del día 1 de marzo de 2021 inclusive, que: "Los contratos de locación o arrendamiento deberán ser registrados dentro de los QUINCE (15) días corridos posteriores a su celebración". Para los contratos celebrados con anterioridad a la vigencia de esta reglamentación se dispone que gozarán de un plazo excepcional para su registración hasta el día 15 de abril de 2021, inclusive.

La ley 27.551 también permite que los locatarios o arrendatarios realicen la declaración del contrato, pero en forma voluntaria, según el artículo 11: "Los sujetos que asuman el carácter de locatarios o arrendatarios en las operaciones económicas previstas por el artículo 2 podrán informar el contrato celebrado a esta Administración Federal, en virtud de lo previsto por el tercer párrafo del artículo 16 de la ley No 27.551 ".

Para los casos de comunicaciones judiciales y resaltando las reservas que mencionamos anteriormente de las características de naturaleza procesal de estas disposiciones, el artículo 13 de la resolución de AFIP dispone:

Para las situaciones contempladas en el segundo párrafo del artículo 16 de la Ley No 27.551, la comunicación de los datos relativos a los contratos se suministrará a esta Administración Federal a través del módulo 
"Comunicaciones Judiciales" del servicio "Registro de Locaciones de Inmuebles - RELI - JUZGADOS".

Los contratos informados por el juzgado interviniente tendrán en el sistema "web" el estado "DENUNCIADO".

Un aspecto curioso a destacar de la resolución de AFIP surge de lo establecido en el Título IV, más precisamente en el artículo 14, el cual dispone que: "Las operaciones concertadas en moneda extranjera deberán informarse en moneda de curso legal considerando el tipo de cambio vendedor del Banco de la Nación Argentina - para la moneda en cuestión-, vigente al cierre del día hábil inmediato anterior al de la celebración del contrato". Con lo cual, para los contratos celebrados en moneda extranjera, la reglamentación además de la registración parece crear una nueva obligación que no está prevista en la ley, la que consistiría en realizar la conversión al valor oficial de dicha divisa al día de la celebración, lo cual puede implicar o demandar de un procedimiento técnico-contable que excede lo establecido por la ley en cabeza del locador como un deber de información.

\section{III.3.5. Resolución anticipada}

La posibilidad de extinguir el contrato de locación en forma anticipada por parte del locatario no resulta novedosa, encontrándose regulado en el artículo 1221 del Código Civil y Comercial. A partir de la sanción de la ley 27.551, la regulación receptada produce modificaciones en relación con las formas de resolución existentes hasta el momento, introduciendo la incorporación del artículo 1221 bis a la cuestión.

En efecto, el artículo 1221 consagra la posibilidad de extinción para el caso de locaciones cuyo objeto sean inmuebles siempre que hayan transcurrido seis (6) meses de contrato. Se establece como carga al locatario el notificar en forma fehaciente su decisión extintiva al locador con un plazo no menor a un (1) mes de anticipación cualquiera sea el destino de la locación. En este supuesto se contempla la fijación de una indemnización la cual varía según la extinción se produzca dentro del primer año de contrato (se debe abonar un mes y medio del canon locativo) o pasado dicho año (se debe abonar un mes de canon locativo). La novedad aparece en los contratos de inmuebles destinados a vivienda, ya que se contempla la posibilidad de notificar al locador con una anticipación de tres (3) meses o más, transcurridos al menos seis (6) meses de contrato, no correspondiendo el pago de indemnización alguna por dicho concepto. Conexión con este supuesto presenta el artículo 1221 bis, en cuanto a que establece que también en los contratos de inmuebles destinados a vivienda, dentro de los tres últimos meses del contrato, cualquiera de las partes puede convocar a la otra a efectos de acordar la renovación del contrato, en un plazo no mayor a quince días corridos. En caso de silencio 
del locador o frente a su negativa de llegar a un acuerdo, estando debidamente notificado, el locatario puede resolver el contrato de manera anticipada sin pagar la indemnización correspondiente.

Por su parte en los casos del artículo 1199 (excepción al plazo mínimo legal), se debe abonar al locador el equivalente a dos (2) meses del valor del canon locativo, conforme al artículo 1.221.

\section{Reflexiones finales}

Sin lugar a dudas, estamos frente a uno de los contratos que, para un gran sector de los argentinos, mayor incidencia tiene en el desarrollo de sus vidas. Su regulación no escapa a la dificultad que representa tal situación, ni tampoco a los vaivenes económicos que caracterizan a nuestro país.

Como se indicó, dada su reciente sanción será el tiempo el que nos permita evaluarla, pero si puede determinarse que constituye una intervención estatal en un mercado muy complejo, y que en parte aumentan la falta de certeza imprescindible para la realización y cumplimiento de contratos de duración como es el caso de la locación de inmuebles.

La actual ley, conocida como "nueva ley de alquileres", como ya hemos visto, se ha propuesto establecer un balance en la dispar relación existente entre el locatario y el locador. No debe de perderse de vista que, por un lado, nos encontramos con el derecho a la propiedad que posee el locador y por otro, el derecho que tienen las personas al acceso a una vivienda digna -en este caso, nos referimos al locatario-. Este conflicto de derechos encuentra su origen en problemáticas socioeconómicas que afronta el Estado a lo largo de su historia.

Particularmente, disposiciones tales como la fijación de un nuevo plazo de duración del contrato tratan de garantizar la permanencia del locatario en el inmueble por un tiempo mayor; cuestiones relacionadas a la actualización del canon locativo o del depósito, o bien la posibilidad del locatario de ofrecer distintas variantes respecto del aporte de garantías debiendo (una de ellas) ser aceptada por el locador, hasta incluso integrando disposiciones que abarcan situaciones en las cuales se presenta la decisión de extinguir dicha relación jurídica, intentan equilibrar el vínculo entre las partes relegando a un segundo plano el derecho de propiedad que poseen los propietarios. Empero escapan de la ley los efectos negativos que provoca a ambas partes, toda vez que existe menor seguridad jurídica y una mayor incertidumbre con relación al negocio contractual.

Tenemos que destacar que, si bien la exigencia de registrar los contratos del artículo 16 de la ley 27.551, reglamentada por la resolución de AFIP 4933/2021, no 
constituye un nuevo impuesto, sí demandará la realización de trámites y gestiones, que de ser encargadas a profesionales, tales como contadores o corredores, generaran un costo extra, a lo que hay que sumarle que dependiendo la situación patrimonial de cada locador, podrá generar modificaciones a su situación impositiva, con los cual estos trastornos y mayores costos afectan directamente la actividad inmobiliaria generando la retracción de la oferta, por un lado, y la suba de los valores de los cánones locativos que los locadores piden por sus propiedades, lo que en líneas generales afecta a los inquilinos que son quienes en definitiva terminan pagando dichos montos.

\section{Bibliografía}

Alterini J. H. (2016). Código civil y comercial de la nación comentado, Tomo VII. Buenos Aires: La Ley.

Aparicio, J. M. (2016). Contratos. Parte General 2. 2da ed. Buenos Aires: Hammurabi.

Calderón, M. R. (2020). Locación y Contratos Afines, 1ra. ed. Buenos Aires: La Ley.

Herrera, M.; Caramelo, G. y Picasso, S. (2015). Código Civil y Comercial de la Nación Comentado. Argentina: Infojus.

Nicolau, N. L.; Hernández, C. (2016). Contratos en el Código Civil y Comercial de la Nación. 1a ed. Ciudad Autónoma de Buenos Aires: La Ley.

Leturia, M. F. y Jalil, S. (2016). Manual del Martillero y del Corredor. 1ra ed. Buenos Aires: Librería Editora Platense S.R.L.

Leturia, M. F. y Jalil, S. (2021). Manual del Martillero y del Corredor. 2da ed. Buenos Aires: Librería Editora Platense S.R.L.

Leiva Fernández, L. F. P. (2017). Tratado de los Contratos Parte Especial. la ed. T. III. Buenos Aires: La Ley.

Lorenzetti, R. L. (2015). Código Civil y Comercial de la Nación Comentado. Argentina: Editorial Rubinzal- Culzoni.

Stiglitz, R. S. (2015) (dir.). Suplemento especial. Contratos. Buenos Aires. La Ley. 


\section{Legislación}

Ley 26.944, Código Civil y Comercial de la Nación. Boletín Oficial de la República Argentina, Buenos Aires, 01/08/2015.

Ley 27.551, Reformas al Código Civil y Comercial de la Nación. Boletín Oficial de la República Argentina, Buenos Aires, 30/06/2020.

Decreto de Necesidad y Urgencia 66/2021. Decreto № 320/2020. Prórroga. Boletín Oficial de la República Argentina, Buenos Aires, 30/01/2021. DECNU-2021-66APN-PTE - Decreto No 320/2020. Prórroga.

Resolución AFIP 4933/2021.

Fecha de recepción: 21-03-2021

Fecha de aceptación: 23-09-2021 